Accounting and Management Information Systems

Vol. 16, No. 2, pp. 291-312

http://dx.doi.org/10.24818/jam is.2017.02004

\title{
The Use of Management Accounting Practices by Romanian Small and Medium-Sized Enterprises: A Field Study
}

\author{
Dan Dacian Cuzdriorean ${ }^{\mathrm{a}, 1}$ \\ ${ }^{a}$ Babes-Bolyai University of Cluj-Napoca, Romania
}

\begin{abstract}
Small and medium-sized enterprises (SMEs) are an important part of each economy all around the world. However, little is known about the taxonomy of both traditional and modern management accounting practices (MAPs) used by SMEs in the process of decision making. In order to address this gap in the literature, this current paper examines the MAPs adopted by the Romanian SMEs. The methodology comprises an analysis of 37 responses to a questionnaire survey carried out among SMEs from one of the most developed regions of Romania. The goal of our study is to determine which tools are being used by Romanian SMEs, and on the other hand, to identify underlying reasons why some specific MAPs are not being used. We find that the large majority of our respondents use a small number of traditional MAPs while most of the modern MAPs documented in the literature and accounting textbooks are very little used. Among the most used traditional MAPs we document the budgeting systems for controlling costs and planning cash flows. On the other hand, the most used modern MAPs were the benchmarking and performance reporting based on financial and non-financial indicators. High costs of implementation, lack of management commitment or financial constraints were the main reasons for the lack of use for certain traditional and modern MAPs. Suggestions for future research and limits are also approached.
\end{abstract}

Keywords: management accounting practices; traditional management accounting practices, modern management accounting practices, SME; Romania

\section{JEL codes: M41}

${ }^{1}$ Corresponding author: Department of Accounting and Audit, Faculty of Economics and Business Administration, Babes-Bolyai University; 58-60 Teodor Mihali St.,

Cluj-Napoca; tel. (+40) 264418 652; email address: dan.cuzdriorean@econ.ubbcluj.ro 


\section{Introduction}

The review of management accounting practices literature in developing countries state for the very fragmented nature of the findings documented, in terms of environment and political conditions, stage of development, orientation towards specific techniques (Albu \& Albu, 2012). Given the fact that little research examined so far the current state of MAPs in SMEs from developing countries, this study is a good opportunity to understand more about such practices in those particular environments. Moreover, as Anderson and Lanen (1999) asserted many years ago, developing countries have the potential to offer unique opportunity for researchers to study the evolution of MAPs in a relative short period of time. In this respect, Romanian SMEs provides the context for conducting this research. Given the fact that SMEs face resource constraints, competitive pressures and large opportunities for rapid growth, understanding the types of MAPs used by them is important for both academia, practitioners and professional associations alike (Nanda, 2010). Overall, given the scarcity of research in this field, assessing the MAPs adopted by Romanian SMEs represents a considerable opportunity that is important to be addressed, we intend to investigate the following three research questions: Which traditional and modern MAPs are used by Romanian SMEs? What is the importance given to MAPs? What are the reasons for the lack of use of certain MAPs in Romanian SMEs?

The motivation for conducting this study is threefold: first, according to the Professional Accountants in Business (PAIB) Committee Comments on the Proposed Framework for Managerial Costing, elaborated by the International Federation of Accountants (IFAC), the management accounting practice is greatly influenced by culture, organization, geography and legal frameworks. In this respect, assessing the MAPs in different contexts is of great interest for both academia and practice on one hand and professional bodies, on the other hand. Second, as the literature indicates there is little evidence on MAPs among SMEs (Armitage et al., 2016). Moreover, extant literature on this subject is largely confined to developed countries, as very few studies were conducted in developing countries (Haldma \& Laats, 2002). In this regard, by addressing this gap, this study builds on previous literature on the use of MAPs by SMEs in a developing country, Romania. Third, the business environment has becoming intensively dynamic and unpredictable in recent years, conducting to more demanding strategies to be used by companies in order to survive and prosper. Managing an SME company is even more difficult when dealing with the goal of achieving competitiveness. In this respect, especially small companies should innovate and apply different strategies and MAPs to be used as main support system for strategy implementation. On the other side, since SMEs all around the world struggle with financing problems, it is expected that little 
innovation to be occurred and therefore the taxonomy of MAPs deserve research attention. Based on the results obtained, the most used traditional MAPs by Romanian SMEs are the budgeting systems used for controlling costs and planning cash flows followed by variance analysis. In terms of modern MAPs, Romanian SMEs managers use both financial and non-financial measures as well as benchmarks followed by competitive position monitoring. Among the reasons for the lack of use of certain traditional and modern MAPs the following were identified: high costs of implementation, the lack of management commitment, financial constraints.

This particular study is seeking to add insights to the limited literature on MAPs in SMEs from developing countries while providing a potential framework for further empirical studies, especially from the Central and Eastern European (CEE) region. As such, this study contributes to the management accounting literature by providing information from to a European perspective of MAPs. The remainder of the paper is organized as follows. The next section briefly sets out the current research in MAPs. Section 3 outlines the research method while the fourth section contains a discussion on the survey results. Conclusions, limitations and implications for future research are presented in a final section.

\section{State of the art}

The need for management accounting information increased over the years, demarche that led scholars to turn their attention on examining MAPs adoption both across countries and type of firms. In this respect, Ittner and Larker (2002) argued that MAPs should be extremely important for each organization since such practices support both the management accounting processes and organizational structure.

Over the time, different professional accounting bodies around the world (The Chartered Institute of Management Accountants in UK; the Institute of Management Accountants assisted by AICPA in USA; the Management Accounting Centre of Excellence of the Australian Society of Certified Practicing Accountants in Australia) founded research regarding the taxonomy of MAPs. The core findings of the research conducted identified and assessed all changes in management accounting function, the drivers of change or examined the tasks performed/required by management accountants. Further, the focus of such studies was bidirectional: traditional versus modern management accounting practices.

In 1998, IFAC ${ }^{\mathrm{i}}$ issued Management Accounting Practice Statement Number 1, designed to be a set of understanding of the scope and purposes of management accounting and 
the concepts which underpin it. Based on this work, scholars assessed the evolution of management accounting in order to survey different stages of MAPs (Abdel-Kader \& Luther, 2006). Given the stages developed according to different representative periods, scholars further differentiated between traditional and modern MAPs, examining the adoption and benefits of both types all over the world (Chenhall \& Langfield-Smith, 1998; Malmi, 2001; Haldma \& Laats, 2002; Lin \& Yu, 2002; Szychta, 2002; O'Connor et al., 2004; Sulaiman et al., 2004; Hyvonen, 2005). Based on previous research conducted, traditional MAPs such as costing, budgeting or profitability analysis focus mostly on cost determination and financial control and have been used extensively by both small and large companies all around the world for many years. Given the new business environment characterized by the advance of competition most of the traditional MAPs were considered out of date and not suitable for today`s new business context. Facing this new context, management accounting was pressured to make important changes in order to maintain its relevance and to meet the current challenges found in management information. As a result, in recent years companies started adopting modern MAPs ${ }^{\mathrm{ii}}$. Being part of the strategic management accounting, modern MAPs are considered a helpful tool in providing useful information about the market in which the company sells its products and the cost and cost structure of competitors. Also, such practices have a complex role of creating value through improved development of resources, while focusing in a more strategic orientation. Introduced by the first time in accounting by Simmonds (1981), this type of accounting is regarded today as monitoring and analyzing the management accounting information of the enterprise and its competitors in order to develop and control the strategy of companies.

In terms of representative periods for both categories of MAPs approached, traditional MAPs are usually associated with the period prior to 1950 and until 1985 and also with the empirical studies conducted prior to 1985 (Khandwalla, 1972; Imhoff, 1978; McNally \& Eng, 1980) while the modern MAPs are usually associated with the period after 1985 to date.

Despite the fact that both traditional and modern MAPs operate as an important facilitator mechanism used to assess and understand the complex nature of the business, previous literature is usually poor on MAPs information in SMEs. However, previous empirical studies seem to focus mainly on assessing the importance and usage of MAPs in large companies from developed countries (Hyvonen, 2005; Abdel-Kader \& Luther, 2008; Angelakis et al., 2010).

Hyvonen (2005) conducted an empirical study in Finland and provide evidence that financial measures like budgeting for controlling costs and product analysis continues to be used and considered important. Also, greater emphasis will be placed on modern 
MAPs like employees' attitudes and customer satisfaction. In UK, Abdel-Kader \& Luther (2008) examined the impact of a range of potentially contingent variables on a broad set of MAPs in a sample of companies selected from one of the largest industry sector. The authors concluded that differences in management sophistication are significantly explained by factors as environmental uncertainty, decentralization, size, customer power, total quality management, Just-in-Time. Angelakis et al. (2010) investigated the extent to which large-size Greek manufacturing companies have implemented various traditional and modern MAPs, the benefits received from those practices and the intentions to focus on specific practices in the future. The results documented by the authors indicated, that, implementation rates for various modern MAPs were of a high level and similar than those presented in other countries. In total, traditionally MAPs were found to be marginally higher implemented than the modern ones.

While it is difficult to draw conclusions about the use of both specific traditional and modern MAPs given the range of geographic areas and industries or variation in size of the companies covered through previous empirical studies, some patterns do arise. For instance, traditional MAPs are still very popular around the world, despite the fact that modern MAPs have superior claimed benefits for companies (Abdel-Kader \& Luther 2006; Sulaiman et al., 2004).

Other pattern of findings documented that little research was conducted in developed countries (Guilding et al., 2000; Joshi, 2001; Lin \& Yu, 2002; Waweru et al., 2004; Van Triest \& Elshahat, 2007; Cinquini \& Tenucci, 2010) where a lack of knowledge concerning the current state of MAPs, can be found, especially when assessing the current state of such practices in SMEs (Sousa et al., 2006; Nandan, 2010).

While it is beyond the scope of this paper to provide an exhaustive review of the literature on MAPs, this section provides a brief overview of studies that have examined the use of MAPs and tools used by SMEs. In this respect, most of the studies we reviewed in this area examined the use of specific MAPs by SMEs, both traditional and modern as: balance scorecard, cash budgets, operating budgets, activity based costing, target costing, economic value added metrics, etc.

For instance, Hudson et al. (2001) examined the way SMEs use performance measurement systems as balanced scorecard. The authors find that SMEs use measurement systems that are not closely linked to firm strategy, and focus heavily on financial metrics. As the authors documented, the managers of such companies tend to develop ad-hoc basis measurement systems when assessing the performance of the 
company. Limited use of performance measurement systems by SMEs where documented also by Sousa et al. (2006). Their work concludes that there is a gap between the theory and practice in terms of performance measurement in English SMEs.

In terms of MAPs implemented by start-up SMEs, Davila and Foster (2005) documented the use of cash budgets and operating budgets while Ilias et al. (2010) documented limited use of specialized techniques as target costing, economic value added metrics or activity-based costing in Malaysian firms. Armitage et al. (2016) also assessed the type of MAPs used by Canadian SMEs. Their findings suggests that Canadian SMEs appear to value the importance of costing systems, operational budgets and the information gained from analyzing the variance from budget expectations. Also, the authors document that the utility of management accounting procedures seems marginal in small Canadian firms.

Several empirical studies have been conducted in Romania, assessing the use and describing the advantages of several management accounting tools, especially modern ones. Other empirical studies were concerned with identifying the factors associated with the existence and use of management accounting techniques in Romanian firms.

The study conducted by Grosu et al. (2014) documented that Romanian accountants seems to prefer mainly MAPs as: Budgets, actual costs (i.e. job order costing, process costing) or activity based costing. Tools as standard costing, variance analysis or balanced scorecard were listed in a lower degree. Other studies like the ones conducted by Albu (2003, 2008), Volkan (2007, 2008) or Almăşan and Grosu (2009) focused on describing modern MAPs as Activity based costing method or Activity based management method together with the advantages brought by the implementation of such practices.

Using a sample of 109 respondents, Albu and Albu (2012) examined the factors associated with the existence and use of MAPs in Romanian firms, and reported that size of the company and type of capital to be dominant in decisions regarding the adoption and use of MAPs. Moreover, the adoption and use of MAPs were mostly associated with the presence of foreign capital. On the other hand, the authors documented limited statistical support for the importance of the environment and competitions, factors usually found to be related to the use of MAPs in other developing countries.

Among the factors limiting the use of MAPs (especially modern ones), the lack of resources is mainly documented (Timans et al., 2012) together with the lack of trainings of employees and difficulty in defining new performance measures (Sousa et al., 2006). 


\section{Methodology}

The survey method is a common one used in managerial accounting. Therefore, this particular empirical study employs a survey (sent online, February-March, 2017) to collect data. All respondents work with Romanian SMEs that have been randomly chosen from Cluj County located in Transylvania region, one of the largest and developed regions of Romania. Out of 100 questionnaires sent to SMEs managers and accountants, 37 were returned. One respondent from each of the company that filled the questionnaires answered and all questionnaires were found to be usable.

Before submitting the questionnaires, a pilot test was conducted in order to refine both the design and the focus of the survey. In this respect an interview was conducted with 2 management accountants who had long experience in the practices of MAPs, both working for 2 large manufacturing companies from the Transylvania region. Such demarche was necessary in order to assess if the questions comprised in the questionnaire content were easy to understand by the respondents. Despite the fact that the questionnaire was applied to SMEs, the decision to use professionals from large companies was taken based on the fact that such professionals have a solid background and understanding of a large taxonomy of MAPs. The idea behind the pilot test was to assess, as stated above, the understandability of the MAPs comprised in the study and as well the taxonomy and finally to compile a list with a large variety of MAPs to be assessed.

General information about the respondents was comprised also in the questionnaire submitted, with reference to: industry sector of the SMEs, type of ownership, educational background, professional qualification status and working experience. For each MAPs included in the second segment of the questionnaire, the respondents were asked if the company used it (yes or no). Respondents were also asked to rate the importance of each MAPs, based on 3-point scale $(1=$ not important; $2=$ moderately important; $3=$ important). At the end, the respondents were asked to summarize the reasons of not using/implementing the MAPs that they marked with "no" in terms of usage.

Demographic data are summarized in Table 1. As can be noticed from the data disclosed in the table below, 5 types of business were identified. Based on the data extracted from the questionnaires returned, the large majority of the SMEs analyzed were from the manufacturing sector (38\%) followed by the property and construction industry (24\%). The least represented sector was the agriculture with a percentage of 5\%. The remaining companies are food industry (19\%) and services (14\%). 
The numbers of employees are below 15 in each of the company comprised in the sample. Analyzing the size of the company, in terms of total assets and net sales, all companies in the sample are either small or very small companies.

The large majority of the respondents held positions as local owner-managers (73\%) followed by accounting managers (5\%) or assistant accounting managers (3\%), operations managers $(11 \%)$, senior costing $(7 \%)$, management accountants $(2 \%)$. The majority of respondents were male (68\%) and aged between 28 and $51(71 \%)$. Most of the respondents had an undergraduate degree only (57\%) with a further $24 \%$ holding a postgraduate diploma and $19 \%$ holding a master degree. Only $36 \%$ of the respondents have a CPA status. The large majority of the respondents had only been in their current position for less than 10 years. Only $8 \%$ of the respondents worked as an accountant for more than 20 years.

Table 1. Profile of respondents $(\mathrm{N}=37)$

\begin{tabular}{llrr}
\hline \multicolumn{1}{c}{ Characteristics } & \multicolumn{1}{c}{ Classification } & Frequency & Percentage \\
\hline Size & Small/very small & 37 & 100 \\
Industry sector & Manufacturing & 14 & 38 \\
& Food industry & 7 & 19 \\
& Property and construction & 9 & 24 \\
& Services & 5 & 14 \\
Ownership & Agriculture & 2 & 5 \\
Education/expertise & Local & 37 & 100 \\
& Undergraduate & 21 & 57 \\
Professional & Postgraduate diploma & 9 & 24 \\
status & Master degree & 7 & 19 \\
Working experience in the field & Less than 5 years & 13 & 36 \\
& Between 5 to 10 years & 24 & 64 \\
& Between 10 to 20 years & 5 & 14 \\
Position hold in the company & More than 20 years & 23 & 62 \\
& Owner - manager & 6 & 16 \\
& Accounting manager & 3 & 8 \\
& Assistant & 27 & 73 \\
& manager & 2 & 5 \\
& Operation manager & 1 & 3 \\
Gender & Senior costing & & \\
& Management accounting & 4 & 11 \\
& Male & 2 & 5 \\
& Female & 1 & 3 \\
& & 25 & 68 \\
\hline
\end{tabular}


In order to examine for response and non-response bias analysis, an independent sample $t$-test was used. The first $20 \%$ of returns and those from the last $20 \%$ were compared to test if responses differed between the two groups. No differences were identified, provided some support for the absence of non-responses bias.

As stated above, in order to assess the current adoption rate of both traditional and modern MAPs used by Romanian SMEs, a list of 49 MAPs (21 traditional MAPs and 28 modern MAPs) was compiled based on the findings documented by previous empirical studies conducted in the literature (Chenhall \& Langfield-Smith, 1998; Guilding et al., 2000; Malmi, 2001; Haldma \& Laats, 2002; Lin \& Yu, 2002; Szychta, 2002; O'Connor et al., 2004; Sulaiman et al., 2004; Hyvonen, 2005; Hyvonen, 2005; Angelakis et al., 2010; Cinquini \& Tenucci, 2010).

The MAPs covered by our survey are summarized in Table 2 (e.g. traditional MAPs) and Table 3 (modern MAPs).

\section{Results and discussions}

Below we present the results of our first two research questions, related to the usage of both traditional and modern MAPs by Romanian SMEs and the importance given to each of the MAPs examined.

While the sample size is small, in total comprising a number of 37 respondents, enough data was provided in order to undertake some preliminary investigation. In this regard, Table 2 and Table 3 shows the frequency of usage for both traditional and modern MAPs, and also the results of the rating of the importance given by each respondent to the MAPs examined.

In terms of traditional MAPs, the budgeting for controlling costs and planning cash flow followed by variance analysis and standard costing were the most used practices. The use of budgets is seems to be significant for the companies in our sample, helping them to control costs and to assist the planning process. The extensive use of budgets in the Romanian companies was documented also by Grosu et al. (2014), followed by MAPs referring to actual costs, activity based costing or standard costs and variance analysis.

Since the budgeting for controlling cash flow is also extensively used in our sample, we can conclude that such practice is used as a control tool for both planning and monitoring cash flow. In Romania, similar results were documented by Jinga and Dumitru (2014), who found the predominance of cost monitoring system. Therefore, as various authors 
from Romania documented previously, the costing techniques are the most used by the companies in this environment, since management accounting is regarded mostly as a cost accounting (Almaşan, 2008).

In this regard, the traditional costing system is preferred by the Romanian companies given it advantages of simplifying the reality and offering a one-dimensional model for the representation of the company`s performance (Grosu et al., 2005). As stated above, standard costing practice was also documented as being used by 11 of 37 respondents in our sample. Given the fact that $38 \%$ of the companies in our sample were from manufacturing area such results are explicable. On the other side there are companies engaging in manufacturing operations and do not employ standard costing where this might be expected. Based on the results obtained, 29\% of our respondents implemented it, contrary to the results documented by Maskell and Baggley (2004) who asserted that managers of small companies do not consider useful this management practice.

For the purpose of illustration, it is helpful to look at the extreme positions disclosed in Table 2. As stated above, four MAPs were found to be indisputably widely used and important (out of 21 MAPs), among which two of them relating to budgeting for controlling costs and planning cash flow. The other two are relating to variance analysis and standard costing. At the end of the ranking, are six traditional MAPs that can be dismissed as peripheral. Among those MAPs budgeting systems for compensating managers, performance evaluation based on divisional profit, formal strategic planning, strategic plans developed separately from budgets, capital budgeting techniques based on net present value and operations research techniques can be found. This observation is also supported by the mean values of perceived importance disclosed in Table 2 for practices as budgeting systems for controlling costs (mean of perceived importance 2.67) compared to capital budgeting techniques based on present value (mean of perceived importance 1.21). Therefore, it can be observed that the mean values for the perceived importance for first four traditional MAPs comprised in the results summarized in Table 2 are noticeably higher than the rest of the MAPs examined. Summarizing the results, it can be noticed that there is a conservatism regarding the use of some traditional MAPs, despite the fact that most of the respondents ranked the large majority of them as being important. 
Table 2. Description statistics of Traditional MAPs in the Romanian SMEs

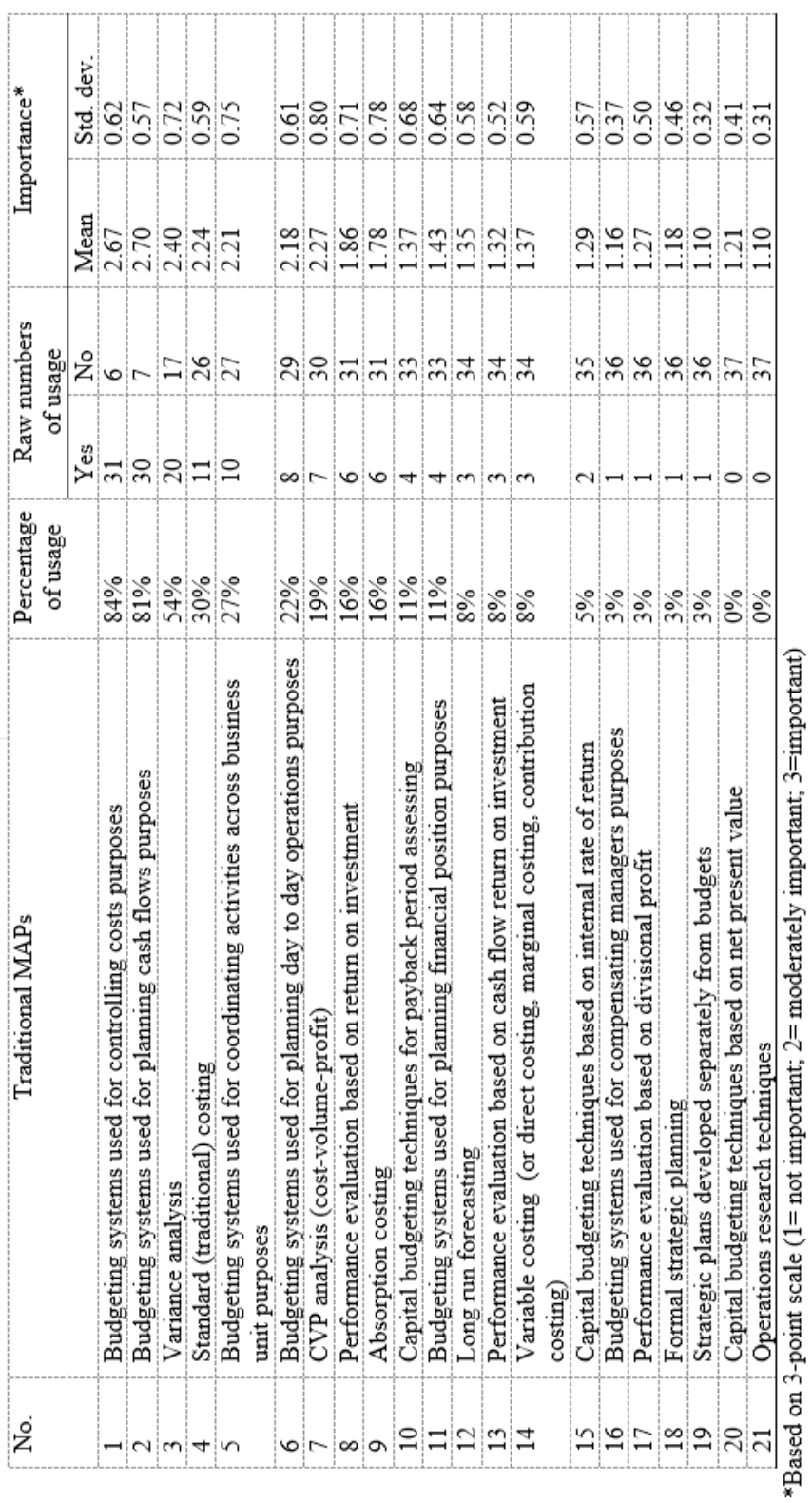

Vol. 16, No. 2 


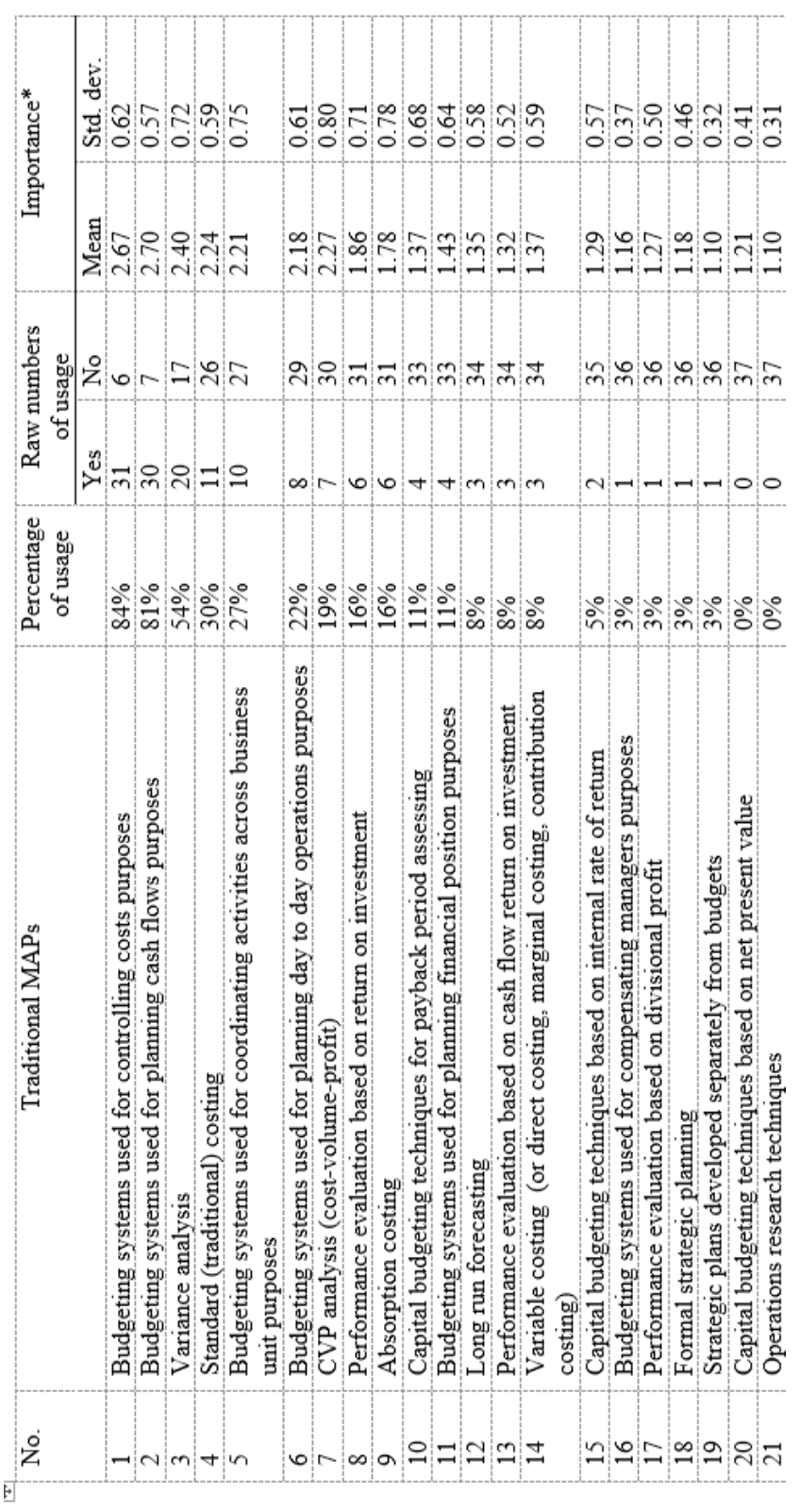

*Based on 3-point scale (1= not important; $2=$ moderately important; $3=$ =important $)$ 
The results of the usage of modern MAPs by Romanian SMEs are summarized in Table 3. For each MAP addressed, the percentage of usage, raw numbers of usage together with the ranking of perceived importance. Analyzing the results disclosed in Table 3 (usage and importance of modern MAPs), it can be noticed that benchmarking, other performance reporting based on both financial and non-financial indicators and competitive position monitoring are the preferred tools in most SMEs examined. At opposite side, modern MAPs strategic costing, Kaizen costing method or value chain analysis seems not to be used at all, but having limited importance (mean of perceived importance ranking from 1.08 to 1.48 ).

As can be noticed from the results summarized in Table 3, performance reporting that combine both financial and non-financial indicators seem to be the most used modern MAP, contrary to the findings documented by Grosu et al. (2005), that Romanian firms tend to ignore non-financial indicators and focus on financial indicators mainly.

In terms of benchmarking, comparing performance with an ideal standard is being used by 9 of 39 of our respondents, with a mean of perceived importance of 2.10. Competitive position monitoring is used by $24 \%$ of our respondents, with a mean of perceived importance of 2.16. As Guilding et al. (2000) documented, this technique was the most used in developing countries as UK, USA and New Zealand. Given the economic environment in Romania, we find this result surprising, and make us wonder if the respondents correctly understood this MAPs.

Based on the results comprised in Table 3, it can notice that the large majority of modern MAPs examined are not used by Romanian SMEs or considered of low importance. In this respect, 7 of 28 modern MAPs are not used (e.g. brand value assessment as basis for managerial decisions, monitoring the financial valuation of the firms' brand, strategic costing, Kaizen method, Economic value added, shareholder value added, value chain analysis) and 12 modern MAPs were assessed as low usage (e.g. target costing, strategic costing, zero-budgeting, Just-in-time costing etc.).

As can be observed from the empirical studies cited above, modern MAPs are considered of highly importance in large companies, but in small companies such tools seems to lack importance. Our results are similar. Moreover, such results regarding the implementation of modern MAPs in SMEs are explicable since small companies usually document very little evidence of strategy. For example, the activity based costing method, found to be one of the most used techniques by companies to achieve strategic effectiveness (Fowzia, 2011; Hyvonen, 2003) in large companies, is not the most used technique in our sample. In practice, its importance is related to the avoidance of 
misleading signals of traditional costing methods. Among the possible explanations is the fact that small firms lack a market or negotiating power and therefore little benefit can be gained from such practice. As it was expected, organizations of that size (small firms) are considerably less likely to employ anything other than very basic management accounting techniques. The results documented by Albu and Albu (2012) regarding size and type of capital can explain also the results obtained. 
Table 3. Descriptive statistics of modern MAPs in the Romanian SMEs

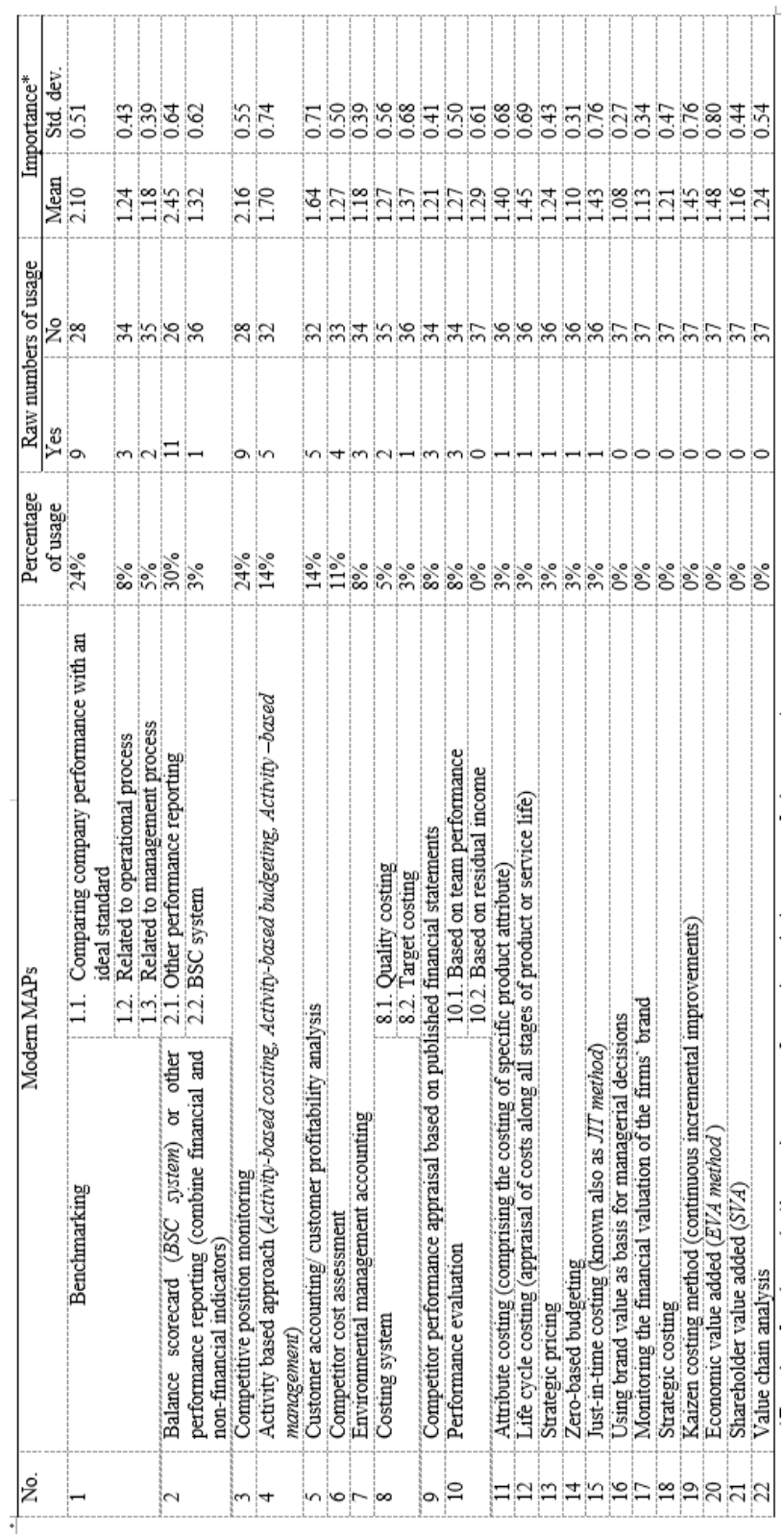

*Based on 3-point scale ( $1=$ not important; $2=$ moderately important; $3=$ important $)$ 
With respect to our third research question, Table 4 summarizes the findings related to the underlying reasons why specific MAPs are not being used by Romanian SMEs. We identified four major factors for each of the category of MAPs examined. In this respect for the traditional MAPs, the four main reasons why such practices are not being used are: (1) the MAP is considered time consuming; (2) low management commitment; (3) the current system is not facing significant problems and (4) financial constraints. In terms of modern MAPs, the main reasons for not adopting such practices are: (1) high cost of implementation; (2) time consuming; (3) the nature of firm`s operations; (4) financial constraints. The results documented are similar to the findings of Armitage et al. (2006).

In search for additional explanations of why the large majority of MAPs addressed are not adopted and used by Romanian SMEs (besides the reasons summarized in Table 4) one can be found in the fact that most of the benefits are not applicable in very small companies where decisions making are centralized (i.e. usually the owner manager is the person in charged with all the decisions). Given the fact that usually SMEs face serious financial constraints, implementing practices that are resource consuming doesn't justify always the associated costs. On the other hand, respondents seems to lack the knowledge of the large majority of modern MAPs, resulting in minimizing the importance given to the large majority of MAPs examined in demarches as: processes improvement, contribution to core strategy or risk reduction.

Table 4. Reasons for not using MAPs (traditional/modern)

\begin{tabular}{lrr}
\hline \multicolumn{1}{c}{ Summarized results } & $\begin{array}{c}\text { Traditional } \\
\text { MAPs (\%) }\end{array}$ & $\begin{array}{c}\text { Modern } \\
\text { MAPs (\%) }\end{array}$ \\
\hline $\begin{array}{l}\text { Do not understand the usefulness/ not appropriate for a small } \\
\text { company/ some practices are too complex }\end{array}$ & 11 & 64 \\
High cost of implementation & 24 & 92 \\
Time consuming & 64 & 87 \\
Educational background/professional experience/ lack of training in & 32 & 57 \\
implementing various MAPs & & 57 \\
Not reliable/noneconomic information & 14 & 57 \\
Current system is not facing significant problems & 57 & 81 \\
The nature of firm`s operations & 32 & 64 \\
Not familiar with this technique/practices. I never heard of it & 24 & 64 \\
Low - management commitment & 64 & 64 \\
Adequate technology/lack of software packages relevant to advanced & 35 & 73 \\
techniques & & 5 \\
Financial constraints & 57 & 14 \\
External stakeholder requirements & 5 & 14 \\
Not part of my working tasks & & \\
\hline
\end{tabular}


As stated above, among the factor influencing the choice of management accounting practices summarized by the respondents can be found: timeliness, existing resources, core functions of the companies. The type of information the company wants to capture for the management decision making is also among the factors influencing the choice of MAPs in Romanian SMEs. Also, the effectiveness and usefulness and some MAPs compared to alternatives was found among the factors influencing the choice of management accounting practices used by the sample.

Comparing the findings of our respondents for both the categories assessed (traditional versus modern MAPs) we can conclude that the latter category is regarded as: more complex, more time consuming, comprising higher costs of implementation, providing more non-economic information, not suitable for the nature of the firm`s operations, not known by the respondents, demanding adequate technology and special software packages. Also, the financial constraints seems to impact much more the implementation of modern MAPs comparing to traditional ones, regarded as less costly. Some of the respondents asserted that implementing MAPs is not part of their job while others pointed out the lack of training.

\section{Conclusion, limits and future research}

The primary focus of this research paper was to examine the traditional and modern MAPs used by Romanian SMEs. A survey was conducted in this regard. Among the traditional MAPs the most used ones are the budgeting systems used for controlling costs and planning cash flows while among the modern ones the use both financial and nonfinancial measures as well as benchmarking. On the other hand, traditional MAPs like budgeting systems for compensating managers, performance evaluation based on divisional profit, formal strategic planning, strategic plans developed separately from budgets, capital budgeting techniques based on net present value and operations research techniques were either not adopted or have a lower adoption rate. In terms of modern MAPs not used by Romanian SMEs the following were found: brand value assessment as basis for managerial decisions, monitoring the financial valuation of the firms ' brand, strategic costing, Kaizen method, Economic value added, shareholder value added, value chain analysis. Beyond that, the utility of these latter approached MAPs seems to be marginal for Romanian SMEs. Among the reasons for the lack of use of certain traditional and modern MAPs the most important ones were related to the high costs of implementation, the lack of management commitment and financial constraints. According to the findings documented by Albu and Albu (2012), the most important factors associated with the existence and use of management accounting techniques are the type of capital and size of the company. Given the fact that we examined only small 
and very small companies with local ownership, our results can characterize this segment of companies from Romania. On the other side, is highly probably that medium and large companies to implement and make use of modern MAPs much often than small ones.

Based on the results obtained, we can document that Romanian SMEs rely heavily on traditional management accounting techniques, while the adoption modern MAPs are rather scarce despite the fact that such techniques are taught in Romanian universities. Moreover, it seems that the large majority of such practices remain at a theoretical level with no connection to the practice level.

As stated above, the large majority of Romanian SMEs are using MAPs which provide information for cost assessment, financial control and accounting information for planning. Similar to the results documented by Chenhall and Langfield-Smith (1998), much more emphasis is being placed on traditional areas of financial analysis, costing and budgeting rather than on strategy.

However, our study is not without limitations. In order to assess the magnitude of both traditional and modern MAPs, the respondents were asked to identify it based on a questionnaire. Such evaluations are always subject to personal bias and sometimes to judgment errors. One potential bias can be the social desirability bias. Other limit consists in the fact that only one research instrument was used (i.e. questionnaire). A further study can comprise the use of both questionnaires and interviews in order to provide more generalizable results.

On the other side, our empirical study involved a limited number of firms concentrated in a particular geographic region, therefore generalizations must be made with caution and future work is needed to expand the breadth of this study. Also, our questionnaire was addressed to both managers and professional accountants, which may have different perspectives on this matter. In this respect, splitting the results based on these two groups, under these circumstances, can be useful for a better understanding of the results. Given the fact that our sample is quite small (37 respondents) and the large majority of the MAPs assessed were not used by our respondents, such demarche was not justifiable.

Given our results and limits, future studies can examine much deeper the reasons for not using modern MAPs, comprising in this regard different methodologies. An in-depth interview can be a useful tool for conducting such demarche, particularly in areas where dissenting findings are apparent (e.g. the use of non-financial indicators by Romanian SMEs). Also, it will be very useful to assess and investigate the perceived benefits from both types of MAPs in Romanian SMEs. 
Our findings can be of interest for both educators and professional bodies in terms of improving dissemination regarding the advantages of both traditional and especially modern MAPs among Romanian SMEs and not only. Also, the results documented by our study can be of high importance to managers in developing countries but also for managers of SMEs all around the world. Lastly, our results raise questions about the usefulness of various MAPs to SME`s leading to the question as to why so many MAPs are not being adopted.

In conclusion, the pursuit of developing and implementing new practices of MAPs by SMEs all around the world is a matter of common effort comprising both learning systems and institutional factors. Summarizing the above, the similarities or dissimilarities of MAPs around the world is certainly an area that is worth assessing more thoroughly in the future.

\section{References}

Abdel-Kader, M. \& Luther, R. (2008) "The impact of firm characteristics on management accounting practices: A UK-based empirical analysis", The British Accounting Review, vol. 40: 2-27

Albu, N. (2003) "Permanence, evolution and innovation in management accounting through ABC", Accounting and Management Information Systems, no. 4: 50-57

Albu, N. (2008) "Activity-based costing system - for whom, for what?" Contabilitatea, Expertiza și Auditul Afacerilor, no. 9: 59-64

Albu, N. \& Albu, C. N. (2012) "Factors Associated with the Adoption and Use of Management Accounting Techniques in Developing Countries: The Case of Romania”, Journal of International Financial Management and Accounting, vol. 23, no. 3: 245-276

Almăşan, A. (2008) "Challenges of a dynamic and complex environment on management accounting", The Annals of the University of Oradea. Economic Sciences, vol. XVII, No. 3: 913-917

Almăşan, A. \& Grosu, C. (2009) "The usefulness of the process approach for value creation in the telecom sector", Accounting and Management Information Systems, vol. 8, no. 4: 521-537

Anderson, S. \& Lanen, W. (1999) "Economic Transition, Strategy and the Evolution of Management Accounting Practices: the Case of India", Accounting, Organizations and Society, vol. 24, no. 5-6: 379-412

Angelakis, G., Theriou, N. \& Floropoulos, I. (2010) "Adoption and benefits of management accounting practices: Evidence from Greece and Finland", Advances 
in Accounting, incorporating Advances in International Accounting, vol. 26: 8796

Armitage, H., Webb, A. \& Glynn, J. (2016) "The Use of Management Accounting Techniques by Small and Medium-Sized Enterprises: A Field Study of Canadian and Australian Practice", Accounting Perspectives, vol. 15, no. 1: 31-69

Chenhall, H. R. \& Langfield-Smith, K. (1998) "Adoption and benefits of management accounting practices: an Australian study", Management Accounting Research, vol. 9, no.1: 1-19

Cinquini, L. \& Tenucci, A. (2010) "Strategic management accounting and business strategy: a loose coupling? Journal of Accounting and Organizational Change, vol. 6, no. 2: 228-259

Fowzia, R. (2011) "Strategic management accounting techniques: Relationship with business strategy and strategic effectiveness of manufacturing organizations in Bangladesh”, World Journal of Management, vol. 3, no. 2: 54-69

Guilding, C., Cravens, K. S. \& Tayles, M. (2000) "An international comparison of strategic management accounting practices", Management Accounting Research, vol. 11: 113-135

Davila, A. \& Foster, G. (2005) "Management accounting systems adoption decisions: vidence and performance implications from early-stage/startup companies", The Accounting Review, vol. 80, no.4: 1039-1068

Grosu, C., Almăşan, A. \& Mariut, L. (2005) "Management accounting between recognition and disappointment", Accounting and Management Information Systems, no. 13-14: 116-121

Grosu, C., Almasan, A. \& Circa, C. (2014) "The current status of management accounting in Romania: the accountants' perception", Accounting and Management Information Systems, vol. 13, no. 3: 537-558

Haldma, T. \& Lääts, K. (2002) "Contingencies influencing the management accounting practices of Estonian manufacturing companies", Management Accounting Research, vol. 13, no. 4: 379-400

Hudson, M., Smart, A. \& Bourne, M. (2001) "Theory and practice in SME performance measurement systems", International Journal of Operations and Production Management, vol. 21, no. 8: 1096-1115

Hyvönen, T. (2003) "Management accounting and information systems: ERP versus BoB", European Accounting Review, vol. 12, no. 1: 155-173

Hyvönen, J. (2005) "Adoption and Benefits of Management Accounting Systems: Evidence from Finland and Australia", Advances in International Accounting, vol. 18, pp. $97-120$ 
IFAC (1998) "International Management Accounting Practice Statement (IMAP \#1): Management Accounting Concepts, Financial and Management Accounting Committee", pp.85, 91-92, 99.

IFAC (2002), Professional Accountants in Business Committee Comments on the Proposed Framework for Managerial Costing, Available at: https://www.ifac.org/publications-resources/paib-committee-response-institutemanagement-accountants-proposed-conceptual (accessed 15 March, 2017)

Ilias, A., Abd Razek, M. \& Yasoa, M. (2010) "The preliminary study of management accounting practices (MAPs) in small business", Global Business and Management Research: An International Journal, vol. 2, no. 1: 79-88

Imhoff, E. A., Jr. (1978) "Management Accounting Techniques: A Survey", Management Accounting, November, 1978: 41-45

Ittner, C. \& Larcker, D. (2002) "Empirical managerial accounting research: Are we just describing management accounting practice?", European Accounting Review, vol. 11, no. 4: 787-794

Jinga, G. \& Dumitru, M. (2014) "The change in management accounting. An institutional perspective for Romania", SEA - Practical Application of Science, vol. II, no. 2(4): 587-594

Joshi, P. (2001) "The International Diffusion of New Management Accounting Practices: the Case of India", Journal of International Accounting, Auditing and Taxation, vol. 10, no. 1: 85-109

Khandwalla, P. N. (1972) "The effect of different types of competition on the use of management controls", Journal of Accounting Research, vol. 20, no. 3: 275-285

Lin, Z., Yu, Z. (2002) "Responsibility Cost Control System in China: a Case of Management Accounting Application", Management Accounting Research, vol. 13, no. 4: 447-467

Malmi T. (2001) “The Practices of Management Accounting in Finland - A Change?", The Finnish Journal of Business Economics, no. 4: 480-501

Maskell, B. \& Baggaley, B. (2004) Practical Lean Accounting, New York: Productivity Press

McNally, Graeme M. \& Lee Hock Eng (1980) "Management Accounting Practices and Company Characteristics", Abacus. December 1980: 142-150

Nandan, R. (2010) "Management Accounting Needs of SMEs and the Role of Professional Accountants: A Renewed Research Agenda", Journal of Management Accounting Research, vol. 8, no. 1: 65-78

O Connor, N., Chow, C. W., Wu, A. (2004) "The adoption of "Western" management accounting controls in China`s state-owned enterprises during economic transition”, Accounting Organization and Society, vol. 29: 349-375 
Simmonds, K. (1981) "Strategic management accounting", Management Accounting, vol. 59 , no. 4: 26-30

Sousa, S., Aspinwall, E. \& Rodrigues, A. (2006) "Performance measures in English small and medium enterprises: Survey results", Benchmarking: An International Journal, vol. 13, no. 1/2: 120-134

Sulaiman M., Ahmad N. \& Alwi N. (2004) "Management Accounting Practices in Selected Asian Countries: A Review of the Literature", Managerial Auditing Journal, vol. 9, no. 4: 493-508

Szychta, A. (2002) "The scope of application of management accounting methods in Polish enterprises", Management Accounting Research, vol. 13: 401-418

Timans, W., J., Ahaus, A. K. \& Van Solingen, R. (2012) "Implementation of lean sixsigma in small and medium sized manufacturing enterprises in the Netherlands", Journal of the Operational Research Society, vol. 63: 339-353

Van Triest, S. \& Elshahat, M. (2007) "The Use of Costing Information in Egypt: A Research Note", Journal of Accounting and Organizational Change, vol. 3, no. 3: 329-343

Volkan, I. R. (2007) "ABC \& ABM - The couple which prevails cost calculation and modern administration for performance", Accounting and Management Information Systems, Supplement: 284-292

Volkan, I. R. (2008) "New perspectives regarding cost calculation", Accounting and Management Information Systems, Supplement: 509-519

Waweru, N., Hoque, Z. \& Uliana, E. (2004) "Management Accounting Change in South Africa: Case Studies from Retail Services", Accounting, Auditing and Accountability Journal, vol. 17, no. 5: 675-704

' IFAC is the global organization for the accountancy profession dedicated to serving the public interest by strengthening the profession and contributing to the development of strong international economies. This organization comprises over 175 members and associates in more than 130 countries and jurisdictions, representing almost 3 million accountants in public practice, education, government service, industry, and commerce.

ii Such as strategic management accounting, balance scorecard, Activity based practices, Just-inTime, Target Costing or value chain analysis. 